\title{
CONTROL AND REMOVAL \\ OF RADIOACTIVE CONTAMINATION \\ IN LABORATORIES \\ OF RADIOACTIVE CONTAMINATION
}

Handbook 48

QC
1
. U51
N0.48
1951

U. S. Department of Commerce National Bureau of Standards \\ NIST
PUBLICATIONS

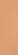

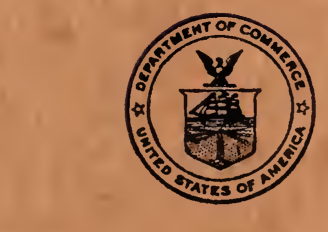

National Bureau of Standards \\ REFERENCE}

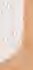




\section{HANDBOOKS OF THE NATIONAL BUREAU OF STANDARDS}

The following Handbooks issued by the Bureau are available by purchase from the Superintendent of Documents, Government Printing Office, Washington 25, D. C., at the prices indicated:

No.

Price

5 American Logging and Sawmill Safety Code. $\$ 0.60$

23 Radium Protection .20

24 American Standard Safety Code for the Protection of Heads, Eyes, and Respiratory Organs .25

Weights and Measures Administration

1.50

27 Safe Handling of Radioactive Luminous Compounds

.10

(1944) Screw Thread Standards for Federal Services

1.00 1950 Supplement.

National Electrical Safety Code

1.75

31 Safety Rules for the Installation and Maintenance of Electrical

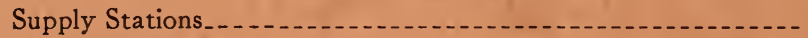

Safety Rules for the Installation and Maintenance of Electrical Supply and Communication Lines.

Safety Rules for the Installation and Maintenance of Electric Utilization Equipment

Safety Rules for the Operation of Electric Equipment and Lines.

35 Safety Rules for Radio Installations

Safety Rules for Electric Fences.

Testing of Weighing Equipment

1.25

38 Protection of Radium During Air Raids

39 Discussion of the National Electrical Safety Code

1.00

41 Medical X-ray Protection Up To Two Million Volts.............

42 Safe Handling of Radioactive Isotopes........................

43 Installation and Maintenance of Electric Supply and Communication Lines. Safety Rules and Discussion..................

44 Specifications, Tolerances, and Regulations for Commercial Weighing and Measuring Devices

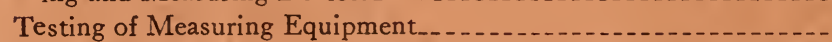

47 Recommendations of the International Commission on Radiological Protection and of the International Commission on Radiological Units 1950

Control and Removal of Radioactive Contamination in Laboratories

49 Recommendations for waste disposal of phosphorus-32 and iodine-131 for medical users 
U. S. Department of Commerce Charles Sawyer, Secretary National Bureau of Standards A. V. Astin, Acting Director

\section{Control and Removal of Radioactive Contamination in Laboratories}

National Bureau of Standards Handbook 48 Issued December 15, 1951 


\section{Preface}

The Advisory Committee on X-ray and Radium Protection was formed in 1929 under the sponsorship of the National Bureau of Standards and with the cooperation of the leading radiological organizations upon the recommendation of the International Commission on Radiological Protection. The committee, small in size, functioned effectively until the advent of atomic energy, which introduced many new and serious problems in the field of radiation protection.

At a meeting of this committee in December 1946, the representatives of the various participating organizations agreed that the problems in radiation protection had become so manifold that the committee should enlarge its scope and membership and should appropriately change its title to be more inclusive. Accordingly, at that time, the name of the committee was changed to the National Committee on Radiation Protection. At the same time, the number of participating organizations was increased and the total membership considerably enlarged. In order to distribute the work load, eight working subcommittees were established as noted below. Each of these committees is charged with the responsibility of preparing protection recommendations in its particular field. The reports of the subcommittees are approved by the main committee before publication.

The following parent organizations and individuals comprise the main committee:

H. L. Andrews, U. S. Public Health Service.

E. G. Williams, U. S. Public Health Service.

Shimlds Warren, U. S. Atomic Energy Commission.

K. Z. Morgan, U. S. Atomic Energy Commission.

L. S. TAYLOR, National Bureau of Standards (Chairman).

M. J. Gross, National Electrical Manufacturers Association.

E. E. Charuton, National Electrical Manufacturers Association.

H. B. Williams, American Medical Association.

R. S. Stone, Radiological Society of North America.

G. FAILla, Radiological Society of North America.

R. R. Newell, American Roentgen Ray Society.

J. L. Weatherwax, American Roentgen Ray Society.

J. E. Wirth, American Radium Society.

E. Quimbx, American Radium Society.

R. C. Peavex, National Bureau of Standards (Secretary).

J. H. Jensen, North Carolina State College.

W. S. Cowart, Lt. Col., Office of the Director of Armament, U. S. Air Forces.

N. Birnbaum, Lt. Col., Army Chemical Center.

W. H. Sullivan, Naval Radiological Defense Laboratory. 
The following are the subcommittees and their chairmen: Subcommittee 1. Permissible Dose from External Sources, G. Failla. Subcommittee 2. Permissible Internal Dose, K. Z. Morgan.

Subcommittee 3. X-rays up to Two Million Volts, H. O. Wyckoff.

Subcommittee 4. Heavy Particles (Neutrons, Protons and Heavier), D. Cowie.

Subcommittee 5. Electrons, Gamma Rays and X-rays above Two Million Volts, L. Marinelli.

Subcommittee 6. Handling of Radioactive Isotopes and Fission Products, H. M. Parker.

Subcommittee 7. Monitoring Methods and Instruments, H. L. Andrews.

Subcommittee 8. Waste Disposal and Decontamination, J. H. Jensen.

With the increasing use of radioactive isotopes by industry, the medical profession, and research laboratories, it is essential that certain minimal precautions be taken to protect the users and the public. The recommendations contained in this Handbook represent what is believed to be the best available opinions on the subject as of this date. As our experience with radioisotopes broadens, we will undoubtedly be able to improve and strengthen the recommendations for their safe handling and utilization. Comments on these recommendations will be welcomed by the committee.

One of the greatest difficulties encountered in the preparation of this Handbook lay in the uncertainty regarding permissible radiation exposure levels, particularly for ingested radioactive materials. The establishment of sound figures for such exposure still remains a problem of high priority for many conditions and radioactive substances. Such figures as are used in this report represent the best available information today. If, in the future, these can be improved upon, appropriate corrections will be issued. The subject will be under continuous study by the subcommittees.

The best available information on permissible radiation levels and permissible quantities of ingested radioactive material may be found in the Recommendations of the International Commission on Radiological Protection and the Supplement to these recommendations in NBS Handbook 47. It must be borne in mind, however, that even the values given in this report may be subject to change.

The present Handbook has been prepared by the Subcommittee on Waste Disposal and Decontamination. Its membership is as follows:

James H. Jensen, Chairman.

W. F. BALE.

W. D. Claus.

Sergei Feitelberg

R. H. Fleming.

JoHN C. Geyer.

G. W. Morgan.

Roy Overstreet.

R. C. Peavey.

Oliver Placak.

EDIth Quimbx.

C. C. Ruchroft.

W. H. Sullivan.

Nathan Woodruff.

A. V. Astin, Acting Director. 


\section{Contents}

Preface

I. Introduction

II. Contamination of the skin

1. General

2. Permissible levels of contamination $\ldots \ldots \ldots$

3. Decontamination procedures $\ldots$

4. Wounds . . . .

III. Clothing and bedding

1. General $\ldots \ldots$

2. Permissible levels of contamination

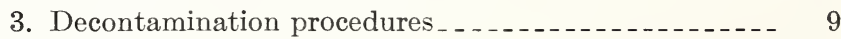

IV. Laboratory tools and glassware

1. Preventive measures____._._._._._. 11

2. Permissible levels of contamination $\ldots \ldots \ldots$

3. Decontamination procedures.

V. Specific materials _...

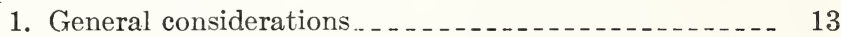

2. Specific materials for use as surfaces of floors, work

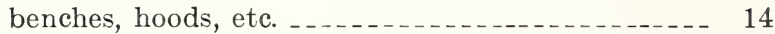

3. Permissible levels of contamination _............ 16

4. Decontamination

VI. Emergencies _....... 18

1. General _............. 18

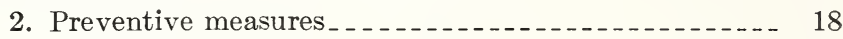

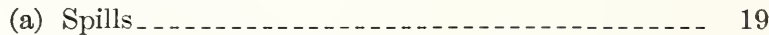

(b) Dusts, mists, fumes, organic vapors, and gases_ 19

(c) Personnel protection ..................... 19

(d) Fires and other major emergencies _........ 20

3. Permissible levels of contamination _._. _..._._. 20

4. Emergency procedures _._.

(a) Minor spills involving no radiation hazard to personnel _.......................... 20

(b) Major spills involving radiation hazard to personnel _............................ 21

(c) Accidents involving radioactive dusts, mists, fumes, organic vapors, and gases............

(d) Injuries to personnel involving radiation hazard

(e) Fires or other major emergencies ............ 22

5. Decontamination_..._._._._. 23

VII. Appendix. Decontaminating detergents and wetting agents_ 23

VIII. References_.......... 


\section{Control and Removal of Radioactive Contamination in Laboratories}

\section{Introduction}

Contamination of the person or of laboratory areas and equipment is a problem of fundamental importance to everyone working with radioactive isotopes. Constant vigilance to prevent contamination, or to contain its spread, must be maintained by every user. The primary concern in this regard is always the protection of workers in the area from the health hazards of potentially dangerous radiations. Furthermore, the maintenance of uncontaminated equipment and laboratories is often paramount if precise and reliable results are to be obtained. Hence, only persons who are properly instructed in procedures that will make their operations safe for themselves and others should be permitted to work with radioactive materials. In laboratories where such operations are varied and extensive, a specialist in radiation protection is mandatory, to determine the appropriate procedures.

Personnel should be thoroughly informed concerning local safety measures and should always be fully aware of all safety devices and recommended emergency procedures before commencing work. Common-sense precautions dictate the use of protective clothing when there is danger of contaminating the person. The principles underlying the use of other safety precautions, such as protective rubber gloves, masks for emergency use, handling tools and forceps, auxiliary containers, etc., should be instilled in each person working with radioactive materials. (Consult NBS Handbook 42.) ${ }^{1}$ Exposed parts of the body and clothing, as well as work areas and equipment, should be monitored frequently (at the beginning and end of each new experiment, and, in many operations, daily thereafter) and thorough surveys should be performed periodically. Personnel should make a habit of

\footnotetext{
1 National Bureau of Standards Handbook 42, Safe handling of radioactive isotopes, prepared by a Subcommittee of the National Committee on Radiation Protection. Superintendent of Documents, U. S. Government Printing Office, Washington 25, D. C., 15 cents.
} 
cleanliness and thorough washing of exposed parts frequently, and as a matter of course before leaving the work areas for any reason.

Experiments with radioactive materials should always be tagged with complete information (date, experimenter, active materials involved, level of activity, special precautions, etc.). Work areas should be posted conspicuously when it is necessary to leave the setup unattended for prolonged periods during which other workers may have access to the area. Suitable placards bearing distinctive symbols to indicate a radiation hazard are available from several sources. Areas known or suspected to be contaminated should also be posted conspicuously and should not be entered by other workers until the proper inspection and clearance can be made. Conversely, areas which it is important to keep clean should also be posted conspicuously. Extreme care should be taken to prevent contamination from reaching halls and offices where personnel not normally working with radioactive materials may come in contact with them.

It is recommended that:

1. There shall be established for each institution working. with radioactive isotopes, an Isotopes Committee whose responsibility shall be the surveillance of all activities involving the handling and use of radioisotopes. This committee shall include in its membership a person experienced in the measurement and handling of radioactive materials and the protection of personnel against ionizing radiations. (Such an Isotopes Committee is now required for this purpose by the Atomic Energy Commission before release of radioactive materials to institutions engaged in medical research, diagnosis, or therapy.)

2. The Isotopes Committee of each laboratory shall designate a competent member of its committee to act as the responsible radiological safety officer (health physicist) for all operations involving radioactive isotopes.

3. The responsibilities of the radiological safety officer (health physicist) shall be to:

(a) review and approve all working areas and protective facilities;

(b) review and approve, or designate by his own authority, precautionary and safety measures for special or unusual operations;

(c) maintain such inspection and monitoring procedures as shall be necessary to insure that persons working with radioactive materials are complying with the designated safety measures and are not working under unsafe conditions;

(d) keep supervisors informed of all radiation exposure 
hazards and other factors affecting permissible working times in a given area;

(e) aid in the solution of new radiation protection problems as they arise;

(f) designate the proper persons to be notified in the event of an emergency: e. g., spills, bodily injury, fire, etc. (A list of such persons should be posted conspicuously in each area where work with radioactive materials is performed);

(g) arrange for the maintenance of adequate records of operations with radioactive materials, and of each individual's radiation exposure.

The recommendations contained in Handbook 42, prepared by a Subcommittee of the National Committee on Radiation Protection, shall constitute a guide in determining the size of the radiological safety group working with the radiological safety officer (health physicist) and the extent of its operations.

4. The Isotopes Committee of each institution shall designate the personnel who shall have entire responsibility for receipt, handling, labeling, storage, issue, disposal and records of all radioactive materials received by the institution.

5. All persons working with radioactive materials shall be familiar with the contents of Handbook 42, and shall comply with its requirements.

The accompanying recommendations and discussions are intended primarily for the guidance of such users of radioactive isotopes as universities, hospitals, and industrial concerns. Those few isotopes that are alpha emitters are not specifically treated in this report. Wherever practical, recommendations are presented separately for groups of isotopes (slight hazard, group I), (moderately dangerous, group II), (very dangerous, group III) in accordance with the arrangement presented in table 1, which is reproduced from Handbook 42. Unless otherwise noted, recommendations or advisory procedures apply to all groups. Furthermore, unless specifically superseded by more stringent recommendations, procedures indicated in this report as desirable for the less dangerous radioactive isotopes should be followed when working with isotopes listed in a more dangerous group; likewise, discussions concerning protective measures required for the low levels of activity apply also to the two higher levels.

For specific methods and monitoring devices the reader is referred to the report of Subcommittee on Monitoring Methods and Instruments of the National Committee on Radiation Protection. For specific safe practices in the handling of isotopes, the reader should consult the report of 
the Subcommittee on Handling of Radioactive Isotopes and Fission Products, National Bureau of Standards Handbook 42 .

\section{TABLE 1. Hazard from absorption into the body.}

Selected radioisotopes grouped according to relative radiotoxicity, with the amounts considered as low, intermediate, or high level, in laboratory practice.

GROUP
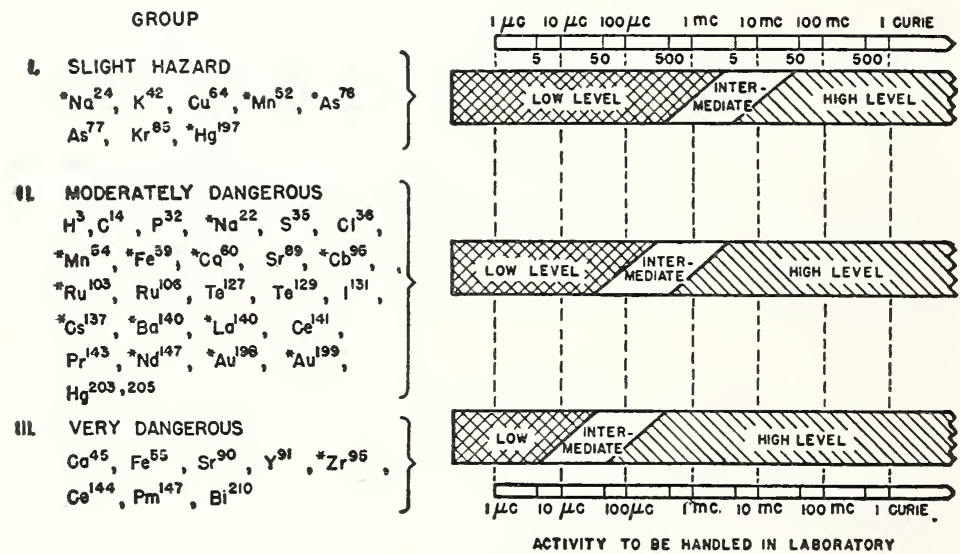

NOTES

Effective radiotoxicity is obtained from a weighting of the following factors:

Half-life.

Energy and character of radiations.

Degree of selective localization in the body.

Rates of elimination.

Quantities involved and modes of handling in typical experiments.

The slant boundaries between levels indicate border-line zones, and emphasize that there is no sharp transition between the levels and the associated protection techniques.

The principal gamma-emitters are indicated by asterisk (e.g., $* \mathrm{Na}^{24}$ ). The above level system does not apply to the hazards of external irradiation.

\section{Contamination of the Skin}

\section{General}

Extreme personal cleanliness is the first rule in preventing contamination of the skin. Persons working with radioactive materials should wash exposed parts of the body frequently and as a matter of routine while on the job. Thorough washing and monitoring shall be mandatory whenever leaving the active area. No edibles of any kind, 
including chewing gum, candy, or beverages, shall be brought into the laboratories, nor shall they be touched before removing all washable traces of radioisotopes from the hands, in accordance with procedures recommended in section II, 3 . (The use of cigarettes or application of cosmetics in the laboratory can result in transference of activity to the lips and skin. Radioisotopes burned on the cigarette may be drawn in to the lungs.)

\section{Permissible Levels of Contamination}

The danger resulting from the contamination of the hands or other parts of the body depends primarily on the type of radioisotopes and level of activity (see section VI, 2, c) and the condition of the contaminated skin. A person should not be permitted to work with radioisotopes if there are open cuts or abrasions on the body. If there are cuts or wounds that may have been contaminated, procedure in section II, 4 , for wound decontamination must be followed immediately. After the body has been washed as explained above, a satisfactory maximum permissible exposure due to spot skin contamination (groups I and II) is $1 \mathrm{mrep} / \mathrm{hr}$ average as measured in a small volume of air (in a thin layer) above any 2 -sq. in. area of the body. If a gamma-emitting radioisotope is the contaminant on the body, this corresponds very approximately (energy of the radiation, self-shielding, geometry corrections, Geiger-Müller tube characteristics, relative amount of beta and gamma present change this value) to a reading of about 1,000 counts per minute when a Geiger counter (with a flat plate area of $2 \mathrm{sq}$. in.) is placed as close as possible to the contaminated area. A thin-walled Geiger counter may be used to measure low-energy beta-emitting contaminants such as $\mathrm{C}^{14}$ or $\mathrm{S}^{35}$. In case of contamination by radioisotopes of group III, the measurable radiation at the surface of the body should be reduced to as near background as possible and the maximum permissible level of contamination is $0.1 \mathrm{mrep} / \mathrm{hr}$ ( $<100$ counts per minute).

If the body is generally contaminated, and especially if contamination is in the eyes or on the gonads, special efforts should be made to reduce the contamination level. If the body (or clothing) is entirely covered with contamination, it should be reduced to $0.1 \mathrm{mrep} / \mathrm{hr}$ ( $<100$ counts per minute), regardless of the group of radioisotopes involved.

\section{Decontamination Procedures}

Thorough washing with soap and water is the best general method for decontamination of the hands and other parts of 
the body, regardless of the contaminant. If the contamination is localized, it is often more practical to mask off the affected area and cleanse with swabs, before risking the danger of spreading the contaminant by general washing.

If the exact nature of the contaminant is known, it may sometimes be more effective to immerse the hands in a suitable reagent immediately after contamination. This should be followed by thorough washing in tepid water with a mild soap, and thorough rinsing in clean water. Detergents and wetting agents may also prove useful, although sometimes a specific one may be required for a particular contamination problem in order to secure maximum cleaning efficiency. A list of detergents and wetting agents that have been used successfully to remove some contaminations is presented in the appendix. The skin may become sensitive following repeated application of detergents to the same area; therefore, care should be taken to avoid this practice. In any case, one must avoid the use of organic solvents that may increase the probability of the radioactive materials penetrating through the pores of the skin.

The recommended procedures for general hand-washing are as follows:

(a) Wash for not less than 2 minutes, nor more than 3 minutes by the clock with a mild pure soap in tepid water with a good lather, covering the entire affected area thoroughly. Give special attention to areas between the fingers and around the fingernails. The outer edges of the hands are readily contaminated and often neglected in the washing. Do not use highly alkaline soaps or abrasives. Rinse thoroughly and repeat, as monitoring indicates, until the desired degree of decontamination is achieved, but not to exceed three or four times.

(b) If the above procedure is not sufficient to remove the contamination, scrub the hands with a soft brush using a heavy lather and tepid water. This scrubbing is primarily to agitate the cleansing agent, and hence prolonged scrubbing without change of reagent is of questionable value. For this reason, at least three washes, including rinses, should be made within 8 minutes, of which at least 6 minutes should be devoted to scrubbing. Only light pressure should be applied to the brush-not sufficient to bend the bristles out of shape or to scratch or erode the skin. Rinse thoroughly and monitor.

(c) Apply lanolin or hand cream to prevent chapping.

Chemicals may be used for cleansing other parts of the body or the hands, if the above procedures do not successfully remove the contamination. There are two processes in 
general use. Procedure (1) outlined below has been used - successfully for heavy contaminations. However, if (1) is unsuccessful, it may be followed by (2), parts A and B.

(1) Apply a liberal portion of titanium dioxide paste to the hands. Work this paste over the affected surface and adjacent areas of the skin for at least 2 minutes. Use water, sparingly, to keep the paste moist. Rinse with warm water, and follow by thorough washing with soap, brush, and water. Be sure that no paste is allowed to remain around the nails. Monitor. Repeat the entire process if necessary.

It should be noted that the condition of the titanium dioxide paste is very important. In order to be effective, the paste must be prepared by mixing precipitated titanium dioxide (a very thick slurry, never permitted to dry) with a small amount of lanolin.

(2) Part A. Mix equal volumes of a saturated solution of potassium permanganate and $0.2 \mathrm{~N}$ sulfuric acid. Pour this over the wet hands, rubbing the entire surface and using a hand brush for not more than 2 minutes. (Note: this application will remove a layer of skin if allowed to remain in contact with the hands too long; consequently, the times stated here should not be exceeded for any single application.) Be sure that all areas are thoroughly covered. Rinse with warm water and proceed as follows:

(2) Part B. Apply a freshly prepared 5-percent solution of sodium acid sulfite $\left(\mathrm{NaHSO}_{3}\right)$ in the same manner as above, using a hand brush and tepid water for not more than 2 minutes. Wash with soap and water, and rinse thoroughly.

The above procedure may be repeated several times as long as the permanganate solution is not applied for more than 2 minutes during any one washing. Applications to other parts of the body than the hands may be facilitated by the use of swabs steeped in the solutions. Lanolin or hand cream should be applied after washing.

A hand decontamination kit should be maintained in each wash room associated with laboratories in which work is done with radioisotopes.

\section{Wounds}

Extreme precautions must be taken to avoid cuts or puncture wounds; this is especially so when working with isotopes of groups II and III, and when working with radioactive isotopes at intermediate or high levels. In the event that the skin is broken in accidents while working with radioactive substances, immediate action should be taken to remove possible contamination. Wash the wound under large 
volumes of running water immediately (within 15 seconds) and spread the edges of the gash to permit flushing action by the water. Light tourniquet action to stop venous return (but not to restrict arterial flow) may be desirable to stimulate bleeding. Report all wounds to the responsible medical or radiological safety officer as soon as emergency precautions have been taken.

\section{Clothing and Bedding}

\section{General}

Protective clothing, personal clothing worn in active areas, and bedding which may have been subjected to contamination, shall be monitored routinely each day, or when one's work with the radioactive material is finished. Articles which show contamination shall be left in the work area, or other designated areas, until they may be decontaminated, or until the activity has decayed to a safe level. For persons working with isotopes in groups II and III, and especially for persons working with intermediate and high levels of radioisotopes, consideration shall be given to the provision of change rooms ${ }^{2}$ where protective clothing may be discarded (or also personal clothing, if necessary). Under no circumstances shall contaminated clothing be worn into clean areas. Where change rooms are not provided, a centrally located shower should be provided for use of personnel working with intermediate and high levels of activity of isotopes in all groups. Personnel should be instructed in the use of this shower.

All clothing or bedding that is known or suspected of being contaminated shall be placed into containers that are provided for that purpose (groups II and III, and intermediate or high levels of activity of group I). Such clothing shall first be marked by the user with his name, the date, and the nature of the contamination. Such clothing shall then be monitored to determine the degree of contamination, held for storage and decay if the contaminant is short lived, laundered if possible, or disposed of in a proper manner. ${ }^{3}$

\footnotetext{
2 Such change rooms should preferably incorporate the "double locker system." This system provides two locker rooms isolated from each other. A worker reporting for work removes all personal clothing in the first room, dons clean sandals, and proceeds to the second locker room where he is provided with work clothes. At the conclusion of his work he returns to the latter room, stores work clothes in an assigned locker if they are to be used again, or passes them through a window to handlers for monitoring and decontamination. Return to the first locker room must then be made through a shower-equipped passage.

3 Recommended procedures for the disposal of radioactive waste are now being prepared by this Subcommittee. These recommendations will be reported in future handbooks.
} 
All handlers engaged in monitoring and decontamination must be provided with protective coats and suitable gloves (all intermediate and high levels).

\section{Permissible Levels of Contamination}

The same levels of maximum permissible contamination that were given in section II, 2 , should be applied to clothing as well as to the skin. They are:

(a) For groups I and II-1 mrep/hr for beta or gamma radiation measured as the average near the surface of the garment. This corresponds to approximately 1,000 counts per minute when a Geiger-Müller counter having a flat plate area of 2 in. ${ }^{2}$ is placed against the garment. (A thin-window Geiger-Müller tube must be used to measure soft beta.)

(b) For group III the radiation level should be close to background (less than 100 counts per minute of beta and/or gamma).

In applying the above levels to the body or clothing, it is usually assumed that most of the radioactivity is contained in a few small spots and not uniformly distributed over the entire body or garment.

\section{Decontamination Procedures}

Decontaminated clothing and bedding should not be released to public laundries unless the contamination is below permissible levels and of short half-life; usually there is no problem in this regard when working at low levels of activity. For clothing and bedding contaminated with radioactive materials having short half-lives, storage is recommended until the contamination is reduced to a safe level; care must be taken, however, to prevent air-borne contamination from clothing placed in storage.

It is sometimes practicable and economical, when working with intermediate or high levels of activity, to place a home type of washer and dryer in a utility room of the laboratory and have a properly instructed person launder the contaminated garments. Effort should be devoted to insuring the use of such facilities in a manner consistent with minimizing the spread of contamination. Special commercial-type laundry facilities are not practical for institutions other than those having extensive operations using radioactive isotopes (large industrial concerns or special hospitals).

If storage or laundering is not practical, it is recommended that contaminated clothing be disposed of in a proper manner (see footnote 3) when above permissible limits. 
Where special laundering facilities are available, each garment shall be monitored to determine the extent of the contamination. In general, this monitoring for hard beta and gamma emitters may be accomplished by closely scanning each garment with a Geiger-Müller counter $\left(30-\mathrm{mg} . / \mathrm{cm} .{ }^{2}\right.$ thickness) of flat plate area of about 2 sq. in., and then measuring the areas of highest activity. When monitoring reveals that clothing is contaminated above the permissible levels stated in section III, 2, laundering may then be attempted. When several levels of contamination are found, it will be desirable to segregate the clothing according to activities (e.g., low, medium, or high) and perform separate laundering operations.

In the selection of any decontamination procedures, the chemistry of the contaminant should be considered. If this is not feasible, one of the following procedures, which have been used in the decontamination of clothing may be desirable:

Garments in each of these classifications should be laundered as follows:

Class 1. (For low activity, less than 1,000 counts per minute for groups I and II, and less than 100 counts per minute for group III): Release for ordinary laundering.

Class 2. (For medium activity, above the activities of class 1 and up to 10,000 counts per minute): Hot rinse, hot rinse, hot solution of 3-percent citric acid wash, hot rinse, hot suds, hot rinse, hot 1.5-percent citric acid wash, three hot rinses, cold rinse, cold rinse, starch if desired, monitor, and repeat if necessary.

Class 3. (For high activity, greater than 10,000 counts per minute):

Laundering procedures identical to those of class 2 , but laundering should be performed separately from garments of a lower classification.

Check each garment after drying by the procedure established for original monitoring for decontamination. If the laundered garments do not fall in class 1, rewash.

Care should be taken that laboratory floors and plumbing are not permitted to become contaminated beyond safe levels. Recommended procedures for their decontamination may be found in subsequent sections.

Rubber gloves and other rubber goods usually decontaminate readily. Such items should first be washed with plenty of suds and hot water. If this does not prove effective, rubber items should be washed in diluted nitric acid. This should be followed by a wash using scouring powder and a thorough rinse in running tap water. Dry on paper towel- 
ing, which should be discarded in the dry active-waste can.

Leather goods cannot easily be decontaminated. Hence shoe covers or rubber overshoes should be worn for protection.

Clothing that cannot be successfully laundered or held for storage shall be regarded as dry radioactive waste and disposed of in accordance with recommended procedures. (See footnote 3.)

"Assault masks" may be decontaminated by washing with soap, a hot 20-percent solution of sodium citrate or other similar agents.

\section{Laboratory Tools and Glassware}

\section{Preventive Measures}

It is desirable to monitor all laboratory tools and glassware before use, unless it is known with certainty that such items are new stock issue. At the same time, care should be taken that no equipment, not immediately necessary to the operations being performed, is brought into the active area. Handling-tools and equipment, when used, should be placed in nonporous metal trays or pans, which are located off to one side, away from the actual working space. It is desirable to line such trays and pans with absorbent disposable paper, which is changed frequently. Auxiliary containers, blotters, and covers shall always be used where danger of spills and contamination of the person or equipment is possible (all groups and levels). Contaminated equipment, or equipment that has been used and is suspected of contamination, should be isolated in designated areas in the laboratory or in suitable storage spaces. A "radiation hazard" label, sticker, or stencil shall be affixed on all containers actually containing, or contaminated with, radioactivity until cleaning can be performed. The use of temporary labels is preferred over permanent stenciling on glassware. Monitoring of equipment and tools shall be a routine procedure following their use, and before release to stock (all groups and levels).

\section{Permissible Levels of Contamination}

The permissible levels of contamination cited in section II, 2, of this report should apply to all laboratory tools and glassware.

\section{Decontamination Procedures}

In the most general terms, decontamination of tools and glassware is undertaken to reduce the hazard to personnel 
using them or to remove radioactive contaminants that might interfere in laboratory experimentation.

Decontamination methods fall into two broad classifications: corrosive and noncorrosive. It is always desirable to use a noncorrosive method, yet this is seldom practical, since removal of the surface layers of material is more effective in putting absorbed ions back into solution than the very slow processes of ion exchange or desorption by noncorrosive methods.

Some of the more common decontamination procedures, involving both corrosive and noncorrosive methods, are given as follows:

All glassware should be washed with acid (chromic acid cleaning solution or concentrated nitric acid) and rinsed, as a routine procedure following use (all groups and levels of activity). All metal tools employed should be surveyed to detect possible contamination (all groups and levels of activity); the use of acid on metal tools may unnecessarily corrode them, causing greater difficulty in future decontamination procedures. Some elements (e. g., iodine) will become volatile upon reaction with acids; in such cases it may be desirable to attempt decontamination first with detergents.

Equipment that is found to be contaminated after the initial treatment shall be stored in an isolated location, possibly in a hood with adequate exhaust or under water, until more thorough decontamination procedures may be applied. If it is necessary to dismantle any equipment prior to decontamination procedures, careful survey should be made during the operation. Contaminated equipment shall not be released from control of the laboratory for repair, or any other purpose, until the level of activity bas been reduced to a safe limit. Where the half-life of the contaminating element is short, it may be desirable to store tools and glassware for decay of activity rather than to attempt decontamination of them. In many cases, if the items are cheap or easily replaced, it may be simpler to dispose of such equipment in a recommended manner (see footnote 3 ) and replace with new apparatus.

Equipment that is contaminated with radioisotopes of groups II or III or with long-lived isotopes and that cannot be satisfactorily decontaminated, must be regarded as radioactive waste and disposed of in a proper manner (see footnote 3 ).

Cleaning of contaminated glassware and tools should be done by designated handlers in a well-ventilated hood set aside in the laboratory for that purpose, or in controlled areas away from the active work laboratories. 
Glass and porcelain articles may be cleaned with mineral acids, ammonium citrate, trisodium phosphate, cleaning solution (chromic acid) or ammonium bifluoride. When the glaze is broken on porcelain, or when active solutions are heated to extreme dryness in glass, decontamination is very difficult, and usually it is more convenient to replace items so treated.

Metal objects may be decontaminated with dilute mineral acids (nitric), a 10-percent solution of sodium citrate, or ammonium bifluoride. When all other procedures fail for stainless steel, use hydrochloric acid. This is a good decontaminant, for the reason that it removes some of the surface; however, this procedure results in etching of the stainless steel, which makes it less desirable for future use. With brass, it has been demonstrated that brass polish is an excellent decontaminant. Plastics may be cleaned with ammonium citrate, dilute acids, or organic solvents.

It should be noted that the effectiveness of a decontaminating process is, for all practical purposes, complete at the end of the second repetition of the process. If necessary, other methods should then be considered for further decontamination.

Laboratory equipment should be surveyed for residual contamination following decontamination procedures. Decontamination seldom exceeds 99.9 percent efficiency and usually runs about 98 to 99.5 percent. If the residual contamination indicates that the level of activity is still greater than that specified as permissible, equipment shall be regarded as radioactive waste. Glass equipment of this nature should be broken up to prevent accidental return to stock or other use.

Glassblowing, welding, brazing, soldering, etc., should never be permitted on equipment contaminated with radioactive materials unless it is done in specially ventilated facilities, and unless special techniques are used to prevent the inhalation of radioactive dust and fumes.

\section{Specific Materials}

\section{General Considerations}

A variety of materials are currently in use for laboratory walls and floors, as well as in work benches and tables on which operations with radioactive materials are performed. In many of the smaller laboratories (i.e., universities, hospitals, etc.) materials are used for such installations that are easily contaminated and that are very difficult to clean. 
This is probably due to the adaptation of existing facilities in these laboratories to work with radioactive isotopes. Because of inherent contamination problems, such laboratories should examine existing facilities very closely and undertake to renovate unsatisfactory installations to facilitate decontamination.

Requirements for coverings in isotopes laboratories are usually more stringent than those found in the chemical laboratories, hospital installations, or general plant facilities from which they have been adapted. Laboratory floors and benches should present a smooth continuous surface, without cracks, and should be of noncorroding, nonporous material. Work benches and tables should be free of sharp corners. It is often desirable, although not always feasible, that work surfaces, floors, and walls be covered with materials that will permit stripping if this becomes necessary.

Floor and benches should be cleaned by wet or oil mopping and dusting only, never with a dry mop, since this may create a dust hazard. Cleaning tools shall be assigned to the room in which the work operations are being performed and not removed or used elsewhere under any circumstances. Organizations baving extensive facilities devoted to work with radioactive materials may wish to consider the installation of a central vacuum cleaning system.

\section{Specific Materials for Use as Surfaces of Floors, Work Benches, Hoods, etc.}

This section is devoted to a brief analysis of the most common types of surfaces in use in radioisotopes laboratories and summarizes the results of a few recent studies on the subject. It is presented for the guidance of radioisotope laboratories that may undertake renovation of existing unsatisfactory facilities, or that may be planning entirely new installations.

(1) Wood.-Not recommended; high porosity, and cracks will gather material too easily; not easily decontaminated.

(2) Concrete.-Not recommended; high porosity and very difficult to decontaminate; painting with strippable plastics will improve considerably, especially for walls; painted floors and work surfaces are subject to too much wear to make this a satisfactory procedure.

(3) Soapstone.-Not recommended; high porosity.

(4) Porcelain.-Not recommended for permanent installations; excessive heat will injure glaze, and may be subject to cracking. Porcelain is suitable for pans and trays, but these should be lined with disposable absorbent material. 
(5) Tile (ceramic).-Acceptable for use in floors if tightly laid and the cracks are well sealed; possibility of cracking tile surface constitutes some hazard, but tile may be replaced.

(6) Asphalt tile.-Recommended; relatively easy to replace if contaminated; tile tends to flow and seal cracks.

(7) Rubber tile.--Recommended for floors if tightly laid and cracks are well sealed; low porosity and resistant to chemical action; tile may be removed if contaminated.

(8) Linoleum.-Acceptable if laid in large sheets; low porosity, especially if waxed; edges and cracks should be well sealed; has the disadvantage that it is difficult to replace in small sections.

(9) Polished stabilized stainless steel (e. g., AISI types No. 304, No. 316, and No. 347).-Recommended, but costly for extensive installations. If used should be kept immaculately clean; these types have good corrosion resistance in the sheet, but are rather easily etched by acid fumes (especially $\mathrm{HCl}$ ). The high polish is good only for the first contamination and removal of this contamination will generally impair the polish.

(10) Plain rolled stainless steel.-Not recommended; steel entraps particles in microscopic pores.

(11) Plate glass.-Recommended; very resistant and easily cleaned; danger of cracking exists.

(12) Tempered glass (e. g., Herculite).-Recommended for table tops and other laboratory work surfaces if used in a single sheet; will not crack, but may shatter under a heavy blow. Glass should be cut to size before being tempered.

(13) Strippable plastics.-Recommended for use in covering work surfaces; low porosity and may be replaced; danger of solution by organic solvents exists.

(14) Paint, varnishes, and lacquers.-Ordinary paints, varnishes, and lacquers are not recommended except for wall protection. Active materials may be absorbed or may combine chemically with paint ingredients; paint may be dissolved by organic solvents. Tygon paint is suitable for some work surfaces and for coating equipment and instruments; care should be taken that this is not allowed to wear off.

(15) Tempered Masonite and Masonite die stock.-Recommended for use in covering work surfaces; low porosity and easily replaced. May be laid in large sheets, but cracks and edges must be well sealed.

(16) Vinyl floor coverings and Vinyl plastic tile.-Recommended; very resistant to ordinary laboratory chemicals and wears exceptionally well; cracks should be well sealed. Danger of solution by some organic solvents exists. 
Where it is necessary to use existing facilities with floors and walls of wood or concrete, extreme care should be taken that all cracks and pores are well sealed. Recommended procedure is as follows:

1. Apply seal coat. This coat must be able to penetrate into the porous material (to a depth of a few millimeters in concrete or wood) and fill the pores with a homogeneous chemically resistant body.

2. Apply first permanent coat. This is preferably a homogeneous extension of the seal coat. It should be resistant to those conditions to which it is expected to be exposed, and should have a low absorption value for the expected radioactive isotope.

3. Apply final surface coat. This may be varied to suit conditions. In addition to the requisite chemical and physical properties, it should have a low susceptibility to contamination, and be readily decontaminated of the expected radioisotopes. An exterior wax finish is often used.

Preliminary investigation of the susceptibility of the coatings to contamination and ease of decontamination for $\mathrm{P}^{32}$, $\mathrm{Ba}^{140}$, and $\mathrm{I}^{131}$ has been carried out by Tompkins, Bizzell and Watson. ${ }^{4}$ The most satisfactory final coatings, considering only the ease of decontamination and the resistance to corrosion by a few of the more common laboratory reagents, were found to be Fluorothene (Carbide \& Carbon Chemicals Corp.), Polythene (Dupont), Duralon No. 35 (U. S. Stoneware Co.), Devon Resin K-5925 (Devoe \& Reynolds Co.), Vinyl Butyrol dispersion D-1000 strippable coat (Monsanto Chemical Co.), and Cocoon-strippable coat (Hollingshead Corp.).

Only proved paints and lacquers should be used for covering floors, walls, or work benches. Danger exists from the absorption or chemical reaction of active materials with paint ingredients, and organic solvents may be used that will remove the paint itself. Moreover, painted surfaces are subject to wear, and experience indicates that repainting must be performed in from 1 to 6 months.

\section{Permissible Levels of Contamination}

The permissible levels of contamination cited in section II, 2, of this report also apply to specific materials used for the surfaces of laboratory walls, floors, work benches, hoods, etc.

1 Radioactive decontamination of laboratory surfaces, II. Paints, plastics and floor materials, by Paul C. Tompkins, Oscar M. Bizzell, and Clyde D. Watson, ORNL-382, Sept. 26, 1949 (see [11] in references). 
In order to keep the general background in the working area low enough for satisfactory instrument operation it is advisable to decontaminate large areas to a level of $0.1 \mathrm{mrep} / \mathrm{hr}$ (100 counts per minute as measured by a thin window Geiger counter of about $2 \mathrm{sq}$. in. flat plate area). Note that the maximum permissible level of contamination is always (regardless of the area involved) $0.1 \mathrm{mrep}$ in the case of contamination by radioactive isotopes of group III.

\section{Decontamination}

Reference is made to decontamination procedures suggested in the previous section that apply to metal, glass, porcelain, and plastic surfaces. Linoleum may be decontaminated by carbon tetrachloride, kerosene, ammonium citrate solution, or dilute mineral acids; care should be taken not to dissolve sealing compounds at the edges and between cracks of the linoleum. Ceramic tile may be decontaminated by the use of mineral acids, ammonium citrate, or trisodium phosphate. Paint is sometimes successfully decontaminated by carbon tetrachloride or 10-percent hydrochloric acid; however, danger of solution of the paint exists, and it is preferable to remove the paint and apply new coatings. Concrete has been successfully decontaminated by the application of 32-percent hydrochloric acid. If this is not successful, no recourse is left except to remove the surface concrete with a chisel. Similarly, contaminated wood surfaces must be planed.

Detergents or wetting agents may frequently be used as successfully as harsher reagents for the decontamination of strippable plastics on polished stainless steel, glass, or other smooth impervious laboratory surfaces. However, the combination of the contaminating conditions, the surface materials, and the cleansing agent are interdependent variables that often influence the decontamination process. A list of some detergents that have been found useful for some decontamination problems is given in the appendix.

Traps and drains may sometimes be decontaminated by the following procedure:

1. Flushing thoroughly with a large volume of water.

2. Scouring with rust remover.

3. Soaking in a solution of citric acid prepared by adding 1 pound of acid to 1 gallon of water.

4. Flushing thoroughly with a large volume of water. 


\section{Emergencies}

\section{General}

Emergencies resulting from accidents in laboratories working with radioactive materials will range from simple spills of small amounts of radioactive materials where no serious contamination problem results to major disasters occurring from explosions, fires, or natural phenomena. Correspondingly, the hazards resulting from such accidents will cover the range of situations from no hazard whatsoever to very serious situations involving extreme radiation hazards and bodily injury, or both. In view of the complicating factors that may arise during such emergencies, simple rules of procedure cannot be set down covering all situations of radiation danger. However, in any emergency primary concern must always be the protection of laboratory personnel from radiation hazards. Second should be the confinement of the contamination to the local area of the accident if this is possible.

Suitable precautionary measures should be taken at the outset jof each operation with radioactive substances to minimize the possibility of accidents; however, each laboratory should also give additional consideration to the procedures that should be followed when an emergency arises. It is of the greatest importance that all personnel should be thoroughly familiar with these precautions and procedures.

In the event of an accident involving radioactive materials, its complete history should be made a part of the laboratory records. This is important to the institution and to the staff for several reasons. Questions of personal health and legal responsibility may depend on such records at some future date. Furthermore, complete records will permit a thorough analysis by the radiological safety officer, which may prevent similar accidents in the future.

\section{Preventive Measures}

Many accidents involving radioactive materials can be avoided if the recommended procedures for safe handling are followed by all laboratory personnel. New techniques and procedures should be approved by the radiological safety officer and, when necessary, tested by dummy runs. Whenever a choice of techniques is available, the one yielding the minimum volume of waste should be selected. Where danger of contaminating the person exists, suitable protective 
clothing and rubber gloves should be mandatory. Workers should be thoroughly familiar with the location of telephones, exits, and all available safety devices.

\section{(a) Spills}

Where danger of spills of radioactive solutions exists, secondary pans and trays should always be used. Containers should be kept covered wherever possible, and only those amounts of radioactive solutions that are immediately necessary should be drawn from stock. Double containers, tightly gasketed, and with chemically inert absorbers, should be used for transporting radioactive solutions if spillage will create a hazardous condition. When feasible, radioactive solutions should be stored in similar containers. Laboratory benches or hoods where spills may occur should not drain to the sewer but to separate containers.

\section{(b) Dusts, Mists, Fumes, Organic Vapors, and Gases}

Adequate forced ventilation is always a first precaution to be considered in laboratories working with radioactive dusts, mists, fumes, organic vapors, or gases. Persons engaged in this work should also be free from respiratory diseases. The use of glove boxes and hoods, provided with adequate exhaust fans, is mandatory. Floors of hoods and glove boxes should be covered with disposable papers to catch dust, spray, or condensate. Radioactive gases and volatile materials, whether in the laboratory or in storage areas, should always be kept in gasketed, gastight containers. Respirators and self-supplied-pressure masks should be available for emergency use. When contamination of the air in the vicinity of the laboratory is a possibility, an air survey should be made to determine the extent of the hazard from radioactivity before extensive operations are begun.

\section{(c) Personnel Protection}

If there is an operation in which radioactive material may be taken into the body by inhalation, ingestion through the skin, or through a wound, it is important to make a careful study of the circumstances and try to estimate the magnitude of the possible hazard. Table 1 lists the three groups of radioactive isotopes: Group I, Slight hazard; Group II, Moderately dangerous; and Group III, Very dangerous. There are low, intermediate, and high levels of each activity, and the level of activity of a particular radioisotope will determine the remedial measures to be taken. First-aid 
materials should be readily accessible to each laboratory working with radioactive materials. All persons in these laboratories should know the proper authorities to be notified following any accident to any personnel.

\section{(d) Fires and Other Major Emergencies}

To protect against the possibility of fire or other major disasters, buildings where radioactive materials are used or stored should be as nearly fireproof as possible. Local fire departments and plant protective personnel should be fully informed in advance of any buildings or areas where major radiation hazards may be encountered. Specified conditions under which it is safe to work should be plainly set forth and thoroughly understood by firemen, guards, police, etc. These conditions should be adhered to unless modified on the scene by the responsible laboratory radiological safety officer. If possible, all radioactive materials in the laboratory not immediately in use should be stored in a nondestructible fireproof safe; such a safe need not be of the vault-type, provided that the available facilities safeguard against possible accidental spread of radioactive contamination in the event of a major disaster.

Persons working with radioactive materials are referred to NBS Handbook 42, for other and more specific preventive measures that shall be followed.

\section{Permissible Levels of Contamination}

The permissible levels of contamination cited in section II, 2, of this handbook shall also apply before work is resumed following any laboratory accident.

Where contamination of the room air is a factor, the maximum permissible level for beta and gamma emitters is $10^{-9}$ microcurie per cubic centimeter of air.

\section{Emergency Procedures}

(a) Minor Spills Involving No Radiation Hazard to Personnel

(1) Notify all other persons in the room at once.

(2) Permit only the minimum number of persons necessary to deal with the spill into the area.

(3) Confine the spill immediately.

Liquid spills:

Don protective gloves

Drop absorbent paper on spill 


\section{Dry spills:}

Don protective gloves

Dampen thoroughly, taking care not to spread the contamination. ${ }^{5}$

(4) Notify the radiological safety officer (health physicist) as soon as possible.

(5) Decontaminate.

(6) Monitor all persons involved in the spill and cleaning.

(7) Permit no person to resume work in the area until a survey is made, and approval of the radiological safety officer (health physicist) is secured.

(8) Prepare a complete history of the accident and subsequent activity related thereto for the laboratory records.

(b) Major Spills Involving Radiation Hazard to Personnel

(1) Notify all persons not involved in the spill to vacate the room at once.

(2) If the spill is liquid, and the hands are protected, right the container.

(3) If the spill is on the skin, flush thoroughly.

(4) If the spill is on clothing, discard outer or protective clothing at once.

(5) Switch off all fans.

(6) Vacate the room.

(7) Notify the radiological safety officer (health physicist) as soon as possible.

(8) Take immediate steps to decontaminate personnel involved, as necessary.

(9) Decontaminate the area. (Personnel involved in decontamination must be adequately protected.)

(10) Monitor all persons involved in the spill and cleaning to determine adequacy of decontamination.

(11) Permit no person to resume work in the area until a survey is made and approval of the radiological safety officer (health physicist) is secured.

(12) Prepare a complete history of the accident and subsequent activity related thereto for the laboratory records.

(c) Accidents Involving Radioactive Dusts, Mists, Fumes, Organic Vapors and Gases

(1) Notify all other persons to vacate the room immediately.

(2) Hold breath and close escape valves, switch off air circulating devices, etc., if time permits.

${ }^{5}$ Water may generally be used except where chemical reaction with the water would generate an air contaminant. Oil should then be used. 
(3) Vacate the room.

(4) Notify the radiological safety officer at once.

(5) Ascertain that all doors giving access to the room are clused and post conspicuous warnings or guards to prevent accidental opening of doors.

(6) Report at once all known or suspected inhalations of radioactive materials.

(7) Evaluate the hazard and the necessary safety devices for safe reentry.

(8) Determine the cause of contamination and rectify the condition.

(9) Decontaminate the area.

(10) Perform air survey of the area before permitting work to be resumed.

(11) Monitor all persons suspected of contamination.

(12) Prepare a complete history of the accident and subsequent activity related thereto for the laboratory records.

\section{(d) Injuries to Personnel Involving Radiation Hazard}

(1) Wash minor wounds immediately, under running water, while spreading the edges of the gash.

(2) Report all radiation accidents to personnel (wounds, overexposure, ingestion, inhalation) to the radiological safety officer (health physicist) as soon as possible.

(3) Call a physician qualified to treat radiation injuries at once. (A list of suitable physicians should be posted near all work areas.)

(4) Permit no person involved in a radiation injury to return to work without the approval of the radiological safety officer (health physicist) and the attendant physician.

(5) Prepare a complete history of the accident and subsequent activity related thereto for the laboratory records.

\section{(e) Fires or Other Major Emergencies}

(1) Notify all other persons in the room and building at once.

(2) Attempt to put out fires if radiation hazard is not immediately present.

(3) Notify the fire department and other local plant safety personnel.

(4) Notify the radiological safety officer (health physicist).

(5) Govern fire-fighting or other emergency activities by the restrictions of the radiological safety officer (health physicist).

(6) Following the emergency, monitor the area and determine the protective devices necessary for safe decontamination. 
(7) Decontaminate.

(8) Permit no person to resume work without approval of radiological safety officer (health physicist).

(9) Monitor all persons involved in combating the emergency.

(10) Prepare a complete history of the emergency and subsequent activity related thereto for the laboratory records.

\section{Decontamination}

Decontamination methods should follow the procedures set down elsewhere in this Handbook.

Where large amounts of radioactive materials may be present, or where danger of contaminating the person exists, workers involved in decontamination shall wear protective clothing, footwear, gloves, and assault masks (pressure-type masks should be used if radioisotopes of groups II or III are involved) as the circumstances dictate.

Where contamination of room air has occurred, thorough ventilation is required, with passage of the air from uncontaminated areas through the contaminated area to the out of doors. Facilities for forced draft exhausts must be built into areas where work with intermediate and high levels of radioactive aerosols or gases are involved in the customary operations.

Following decontamination, work shall not be resumed in any area without the approval of the radiological safety officer (health physicist).

\section{Appendix. Decontaminating Detergents and Wetting Agents ${ }^{6}$}

(Cleaning reagents and manufacturers)

0.1\% Nytron. Allied Chem. \& $1 \%$ S-189. Jacques Wolf \& Co. Dye Co.

$1 \%$ Nytron. Allied Chem. \& Dye Co.

$1 \%$ Sequestrene A. A. Alrose Chem. Co.

$1 \%$ Amine O. Alrose Chem. Co.

$1 \%$ Rynsynol. Alrose Chem. Co.

$1 \%$ Tergitol WA \#4. Carbide \& Carbon Chem. Corp.

$1 \%$ Solvadine EO. Ciba Co. $1 \%$ Product QB. DuPont Corp. $10 \%$ CMS (DuPont Corp.) and $1 \%$ S-189.

$1 \%$ BTC. Onyx Oil \& Chem. Co.

$1 \%$ Phil-O-Sol. Onyx Oil \& Chem. Co.

$1 \%$ D2-389. Rohm \& Haas Co. $1 \%$ Triton 720. Rohm \& Haas Co.

$1 \%$ Triton 770. Rohm \& Haas Co.

$1 \%$ Mulsor 224. Synthetic Chem., Inc.

$1 \%$ Mulsor 224 and $10 \%$ CMS.

Most of the common household detergents, such as Tide, Dreft, etc., have been used successfully.

${ }^{6}$ See [11] in References. 


\section{References}

[1] P. C. Tompkins, A. Broido, and J. D. Teresi, MDDC 377 (June 4, 1946).

[2] S. F. Forkner and L. J. Deal, M-3995 (June 6, 1946).

[3] P. Britton, P. Sears, C. S. Prosser, and E. Tyre, IIDDC-1243 (1947).

[4] W. B. Lewis, HRAC-35 (Aug. 18, 1947).

[5] P. C. Tompkins, MDDC-1414 (Sept. 1947).

[6] P. C. Tompkins, Naval Medical Bulletin, p. 164 (MDDC-1527) (March-April 1948).

[7] Chem. Div. Committee on Health and Safety, Argonne Nat'l. Lab., ANL-4146 (AECU-168) (May 3, 1948).

[8] G. H. Guest, NRC-1878 (June 15, 1948).

[9] B. H. Webb, KAPL-175 (Aug. 6, 1948).

[10] P. C. Tompkins and O. M. Bizzell, Ind. Eng. Chem. 42, 1469 (Aug. 1950).

[11] P. C. Tompkins, O. M. Bizzell, and C. D. Watson, Ind. Eng. Chem. 42, 1475 (Aug. 1950).

[12] R. P. Hammond, LAMS-911 (AECD-2711) (Oct. 3, 1949).

Submitted for the National Committee on Radiation Protection.

Lauriston S. Taylor, Chairman.

Washington, February 15, 1951. 

